\title{
Urinary monocyte chemotactic protein-1 (MCP-1) in leprosy patients: increased risk for kidney damage
}

\author{
Gdayllon Cavalcante Meneses ${ }^{1}$, Alexandre Braga Libório ${ }^{2 *}$, Elizabeth Francesco de Daherr ${ }^{2}$, Geraldo Bezerra da Silva Jr ${ }^{5}$, \\ Marcus Felipe Bezerra da Costa ${ }^{1}$, Maria Araci Andrade Pontes ${ }^{3}$ and Alice Maria Costa Martins ${ }^{4}$
}

\begin{abstract}
Background: We aimed to evaluate urinary MCP-1 and oxidative stress through urinary malondialdehyde (MDA) in leprosy and correlate them with traditional, but less sensitive markers of renal disease.

Methods: This is a cross-sectional study of 44 patients with diagnosis of leprosy and no previous treatment. Skin smear was assessed through a bacteriological index - from 0 to $6+$. Glomerular filtration rate (GFR), protein excretion rate, microalbuminuria, urinary oxidative stress, malondialdehyde (MDA) and urinary MCP-1 were measured. Also, high- sensitivity C-reactive protein (hs-CRP) was measured in the blood. Fifteen healthy subjects composed a control group.

Results: Age and gender were similar between leprosy patients and control groups. No patient had a GFR $<60 \mathrm{~mL} / \mathrm{min} /$ $1.73 \mathrm{~m} 2$ or albumin excretion rate greater than $30 \mathrm{mg} / \mathrm{g}-\mathrm{Cr}$. Leprosy patients had higher urinary protein excretion (97.6 \pm 69.2 vs. $6.5 \pm 4.3 \mathrm{mg} / \mathrm{g}-\mathrm{Cr}, \mathrm{p}<0.001)$, urinary MCP-1 (101.0 \pm 79.8 vs. $34.5 \pm 14.9 \mathrm{mg} / \mathrm{g}-\mathrm{Cr}, \mathrm{p}=0.006)$ and urinary MDA levels $(1.77 \pm 1.31$ vs. $1.27 \pm 0.66 \mathrm{mmol} / \mathrm{g}-\mathrm{Cr}, \mathrm{p}=0.0372)$ than healthy controls. There was a positive correlation between urinary MCP-1 and bacteriological index in skin smears $(r=0.322, p=0.035)$, urinary protein excretion $(r=0.547, p<0.001)$, albumin excretion rate $(r=0.414, p=0.006)$ and urinary MDA $(r=0.453, p=0.002)$. After adjusting for $h s-C R P$, urinary MCP-1 remained correlated with albumin excretion rate $\left(r_{\text {partial }}=0.483, p=0.007\right)$ and MDA levels $\left(r_{\text {partial }}=0.555, p=0.001\right)$.

Conclusion: Leprosy patients with no clinical kidney disease have increased urinary MCP-1 mainly in lepromatous polar form. Inflammatory (MCP-1) and oxidative stress markers suggest leprosy patients are at high risk of developing kidney disease.
\end{abstract}

\section{Background}

Leprosy, a chronic infectious disease caused by the obligate intracellular bacterium Mycobacterium leprae, remains a major source of morbidity in developing countries. The disease affects mainly the skin and peripheral nervous system, but it has a wide range of clinical and histopathological manifestations. Depending on the degree and efficacy of cell-mediated immunity, patients can present with a single, well-demarcated lesion - polar tuberculoid (TT) or, on the other extreme, with numerous, poorly demarcated, raised or nodular

\footnotetext{
* Correspondence: alexandreliborio@yahoo.com.br

${ }^{2}$ Department of Clinical Medicine, Faculty of Medicine, Federal University of Ceará, Fortaleza, Ceara, Brazil

Full list of author information is available at the end of the article
}

lesions on all parts of the body, which constitutes polar lepromatous (LL) leprosy. Other patients, however, fall into a broad borderline category between these two polar forms; this is subdivided into borderline lepromatous (BL), mid-borderline (BB), and borderline tuberculoid (BT) [1,2].

Renal lesions in leprosy patients can be present in up to $72 \%$ of leprosy patients in autopsied patients [3]; however, clinical manifestation can be subtle. Only a few patients show a fast decline in renal function or major proteinuria associated with edema. These uncommon cases are published as case reports, due to their rarity $[4,5]$. Many other leprosy patients can be at risk for developing kidney disease. Identification of these patients is difficult in part due to lack of sensitivity of diagnostic 
tests used in clinical practice to detect incipient renal disease.

The monocyte chemotactic protein-1 (MCP-1) is one of the new recently studied renal biomarkers. This protein is expressed in injury and inflammation sites and directs the recruitment of macrophages, which bind to chemokine receptors to promote macrophage adhesion and chemotaxis. The renal increase in MCP-1 expression can occur in progressive kidney disease and when there is interstitial inflammatory infiltrate [6]. Urinary MCP-1 has been associated with increased albuminuria in patients with other renal diseases, such as diabetes [7]. Also, investigations suggest that oxidative stress plays a pivotal role in the pathogenesis, progression, and complications of kidney disease [8]. Several urinary biomarkers of oxidative stress have been studied in the context of progressive kidney disease $[9,10]$.

In the present study, we aimed to evaluate urinary MCP-1 and oxidative stress through urinary malondialdehyde (MDA) in leprosy patients in comparison with a healthy control group and correlate them with traditional, but less sensitive markers of renal disease. In addition, we compared patients according to bacilli smear positive cases and polar leprosy clinical picture.

\section{Methods}

This is a cross-sectional study of 44 patients with clinical and laboratory diagnosis of leprosy. Data were collected among patients diagnosed with leprosy with no previous anti-mycobacterium treatment. Patients were recruited in public health centers from Fortaleza, state of Ceara, Brazil between August 2012 and August 2013. This study protocol was approved by the Ethical Committee of Walter Cantidio University Hospital, Universidade Federal do Ceara, Brazil (N. 267.426) and all participants signed informed consent. Exclusion criteria included: patients with known previous renal disease (according to Kidney Disease Outcomes Quality Initiative recommendations - glomerular filtration rate higher than $60 \mathrm{~mL} /$ $\mathrm{min} / 1.73 \mathrm{~m}$ [2] and albumin excretion rate less than $30 \mathrm{mg} / \mathrm{g}-\mathrm{Cr}$ ), diabetes mellitus, systemic lupus erythematosus, arterial hypertension and erythema nodosum leprosum reaction episode. Also, a group of 15 healthy subjects were included as a control group.

The following data were collected: age, gender, time of symptoms, use of other concomitant drugs, number of skin lesions, skin smear microscopy, systolic and diastolic blood pressure. Leprosy was classified clinically as tuberculoid polar form (TT and BT), mid-borderline (BB) and lepromatous polar form (BL and LL). Also, patients were classified regarding smear-positivity as paucibacillary (no bacilli smear-positive) or multibacillary. Skin smear was assessed through a bacteriological index - from 0 to $6+[2]$. Serum creatinine and high-sensitivity
C-reactive protein (hs-CRP) were measured. Additionally, a morning urine sample (after approximately an 8-hour fasting period) was collected and creatinine, total protein, microalbuminuria, MDA and MCP-1 levels were measured. All urine measurements were normalized by urinary creatinine concentration. Glomerular filtration rate (GFR) was estimated using CKD-EPI equation.

The analytical methods used for creatinine and urine protein excretion, measurement were colorimetric methods $\left(\right.$ Labtest $\left.^{\circ}\right)$. C-reactive protein (CRP) and microalbuminuria were quantified by automated immunoturbidimetry (Cobas C 111, Roche ${ }^{\circ}$ ). Urinary malondialdehyde (MDA) was isolated and quantified using the thiobarbituric acid (TBARS) test. Urinary MCP-1 was determined by sandwich enzymelinked immunosorbent assay (ELISA) (Boster Biological Technology, Fremont, CA, USA).

Data were tested for normal distribution and are shown as mean \pm S.D. Groups were compared using t-student test or one-way-ANOVA with Bonferroni post-test. Correlations were performed using Pearson's coefficient. A p-value less than 0.05 was considered significant.

\section{Results}

A total of 44 patients (63.6\% males) with a mean age of $36.1 \pm 10.6$ years old were selected. Additionally, 15 healthy patients were selected as controls - mean age $35.4 \pm 9.2$. Time from symptom onset to leprosy diagnosis ranged from one month to 8 years, with a median time of 17 months. Twenty-six patients had positive skin-smear test (multibacillary - MB) and 18 were paucibacillary - PB. Clinically, there were 14 TT/BT, 19 BB and $11 \mathrm{LL} / \mathrm{BL}$ leprosy patients. Regarding renal function, no patient had chronic kidney disease according to Kidney Disease Outcomes Quality Initiative definition - glomerular filtration rate higher than $60 \mathrm{~mL} / \mathrm{min} / 1.73 \mathrm{~m} \mathrm{[2]} \mathrm{and} \mathrm{albu-}$ min excretion rate less than $30 \mathrm{mg} / \mathrm{g}-\mathrm{Cr}$.

Leprosy patients had higher urinary MCP-1 (101.0 \pm 79.8 vs. $34.5 \pm 14.9 \mathrm{mg} / \mathrm{g}-\mathrm{Cr}, \mathrm{p}=0.006)$ and urinary MDA levels $(1.77 \pm 1.31$ vs. $1.27 \pm 0.66 \mathrm{mmol} / \mathrm{g}-\mathrm{Cr}, \mathrm{p}=0.0372)$ than healthy controls. Also, urinary protein excretion was higher in leprosy patients when compared to controls $(97.6 \pm 69.2$ vs. $6.5 \pm 4.3 \mathrm{mg} / \mathrm{g}-\mathrm{Cr}, \mathrm{p}<0.001)$. Moreover, there was a stepwise increment in urinary MCP-1 and urine protein excretion rate values from tuberculoid to lepromatous type in leprosy patients - see Figure 1. Urinary MCP-1 was higher in multibacillary than in paucibacillary patients $(122.1 \pm$ 91.9 vs. $72.0 \pm 46.1 \mathrm{mg} / \mathrm{g}-\mathrm{Cr}, \mathrm{p}=0.023)$ and there was a positive correlation between urinary MCP-1 and bacteriological index in skin smears $(r=0.322, p=0.035)$. No significant correlation between urinary MCP-1 and time of symptoms was observed $(\mathrm{r}=0.014, \mathrm{p}=0.938)$.

Although there was no correlation between glomerular filtration rate and urinary MCP-1 levels $(r=-0.018, p=$ 0.906), urinary MCP-1 was correlated with urinary protein 


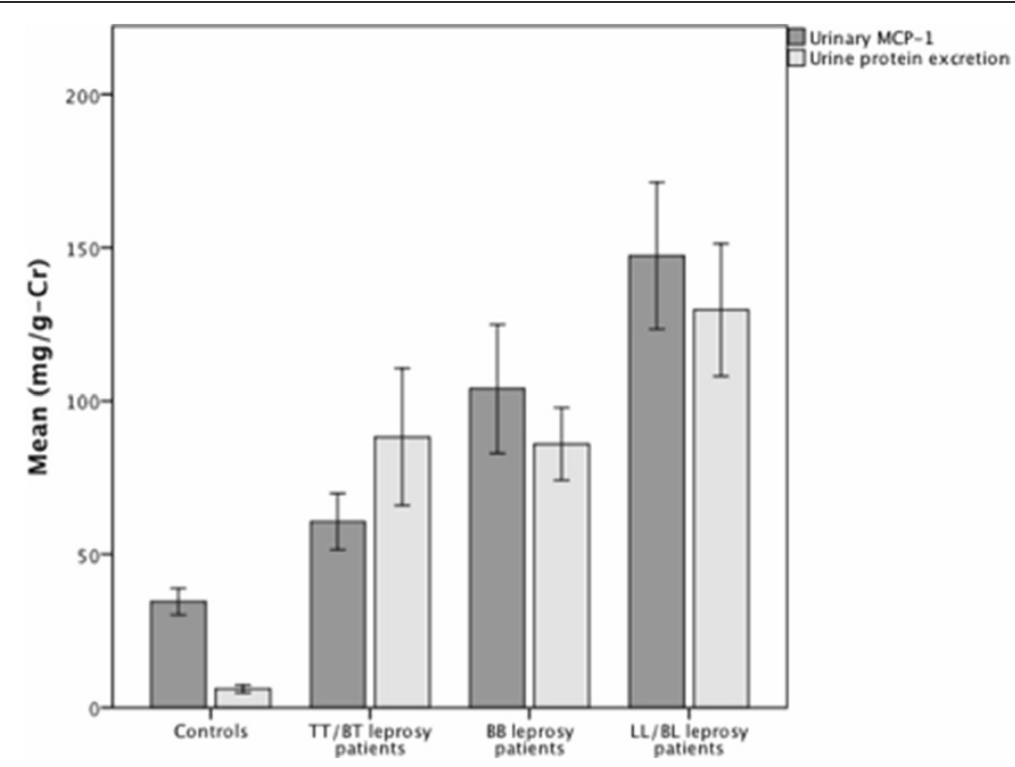

Figure 1 Urinary MCP-1 and protein excretion in controls and leprosy patients according their clinical classification.

excretion $(\mathrm{r}=0.547, \mathrm{p}<0.001)$, albumin excretion rate $(\mathrm{r}=0.414, \mathrm{p}=0.006)$ and urinary MDA $(\mathrm{r}=0.453, \mathrm{p}=$ $0.002)$ - Figure 2. To exclude the possibility that elevated urinary MCP-1 would be only a reflex of systemic inflammation, we also measured serum hs-CRP and there was no correlation between both markers $(\mathrm{r}=-0.095, \mathrm{p}=0.606)$. After adjusting for hs-CRP, urinary MCP-1 remained correlated with albumin excretion rate $\left(\mathrm{r}_{\text {partial }}=0.483, \mathrm{p}=0.007\right)$ and MDA levels $\left(\mathrm{r}_{\text {partial }}=0.555, \mathrm{p}=0.001\right)-$ Table 1 .

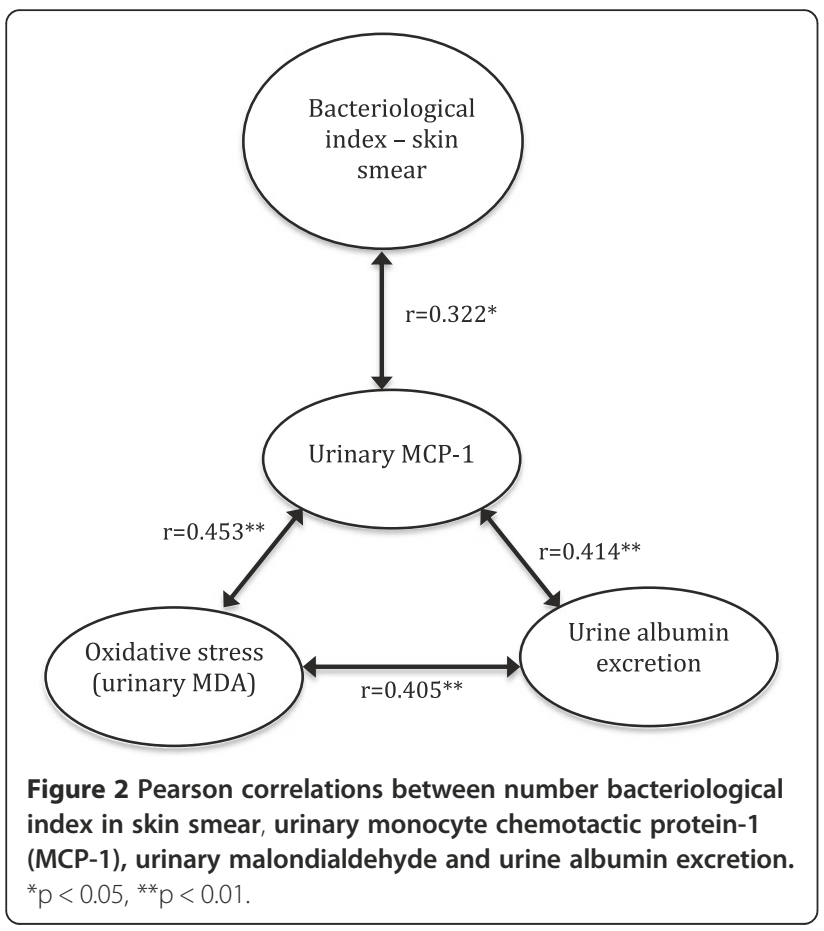

\section{Discussion}

In the present study, leprosy patients with no clinical kidney disease had increased urinary MCP-1 and MDA, new markers of kidney disease progression. Moreover, patients with multibacillary and lepromatous polar form of leprosy had increased levels of urinary MCP-1. Albumin excretion rate, a known marker of kidney disease progression, correlated with urinary MCP-1. Also, there was a positive correlation between urinary MCP-1 and MDA.

Leprosy patients can present with kidney disease of glomerular (glomerulonephritis/amyloidosis) or tubuleinterstitial etiology. Generally, these patients present clinically with overt proteinuria or reduced GFR. Although they have been well described, these pathologies are not common and are generally published as case reports. However, leprosy patients have an increased risk of developing chronic kidney disease and subclinical renal lesions can be a common event [11]. In this study, leprosy patients with no clinical kidney disease showed increased levels of urinary MCP-1. This is a relatively

Table 1 Pearson and partial correlation between MCP-1 and others parameters of renal function/biomarkers

\begin{tabular}{lcccc}
\hline & $\begin{array}{c}\text { Pearson } \\
\text { correlation }\end{array}$ & $\mathbf{P}$ & $\begin{array}{c}\text { Partial correlation } \\
\text { (adjusted for hs-CRP) }\end{array}$ & $\mathbf{p}$ \\
\hline $\begin{array}{l}\text { Glomerular } \\
\text { fitration rate }\end{array}$ & -0.018 & 0.906 & 0.002 & 0.934 \\
$\begin{array}{l}\text { Urinary protein } \\
\text { excretion }\end{array}$ & 0.547 & $<0.001$ & 0.526 & 0.002 \\
$\begin{array}{l}\text { Albumin excretion } \\
\text { rate }\end{array}$ & 0.414 & 0.006 & 0.483 & 0.007 \\
\begin{tabular}{l} 
Urinary MDA \\
\hline
\end{tabular} & 0.453 & 0.002 & 0.555 & 0.001 \\
\hline
\end{tabular}

Hs-CRP: high-sensibility C-reactive protein; MDA: malondialdehyde. 
new biomarker that has been associated with kidney disease progression in other pathologies, such as diabetic nephropathy. Although patients with active lupus nephritis [12] had higher urinary MCP-1 levels than leprosy patients; these had urinary MCP-1 level comparable to diabetic patients with microalbuminuria [13].

Interestingly, urinary $\mathrm{MCP}-1$ levels were correlated with the lepromatous polar form and the bacteriological index in skin smears. This correlation is probably due to increased immunocomplexes in renal disease in multibacillary patients, resulting in higher inflammation burden. However, we cannot exclude the possibility that a predominant $T_{h} 2$ immune response can be responsible for renal inflammation in these patients. Monocyte chemoattractant protein -1 has been recognized as a crucial factor for the development of adaptive $\mathrm{T}_{\mathrm{h}} 2$ responses [14], making the second hypothesis plausible.

Urinary oxidative stress was increased in leprosy patients and correlated with urinary MCP-1 levels. Recently, kidney MCP-1 expression was correlated with oxidative stress in diabetic nephropathy [15]. According to Figure 2, we suggest that increased MCP-1 levels increase renal oxidative stress, contributing to renal damage.

Both urinary MCP-1 and oxidative stress correlated with urinary protein and albumin excretion rate. Urinary albumin excretion rate is a known marker of kidney disease progression and studies have indicated a continuous risk increment with high levels of urinary albumin excretion, even when it remains within the normal range [16]. This fact indicates that leprosy patients can be at risk of developing advanced renal disease in the future. Considering that more than $15 \%$ of leprosy patients can show elevated urine albumin excretion [17], urinary MCP-1 can be a useful early biomarker to identify patients at risk. Although, leprosy is not a recognized cause of clinical kidney disease, it may be due to the long time to developing chronic kidney damage. It is probable that a long-term follow-up in leprosy patients can detect a higher incidence of chronic kidney disease in comparison with normal population.

The possibility that urinary MCP-1 was only a manifestation of systemic inflammation was considered, but even after adjusting for hs-CRP, urinary MCP-1 remained correlated with urine albumin and protein excretion rates, indicating that renal MCP-1 expression is increased in these patients, regardless of systemic inflammation.

The main limitation of the present study is its crosssectional design. Because of its design, we cannot affirm there is a causal relationship between urinary MCP-1, oxidative stress and urinary albumin excretion. Also, cohort prospective studies are necessary to determine whether these subclinical renal alterations will develop into the clinically manifest disease.

\section{Conclusion}

We demonstrated that leprosy patients with no clinical kidney disease have increased urinary MCP-1 and its levels are even higher in patients with the lepromatous polar form. Moreover, urinary MCP-1 was associated with urinary oxidative stress and urinary albumin excretion, suggesting these patients are at increased risk of developing clinical kidney disease.

\section{Competing interests \\ All authors declare that they have no competing interest.}

\section{Authors' contributions}

GCM, MFBC, GBSJ and MP collected the data. ABL, EFD, AMCM designed the study. GCM, MFBC, GBSJ and MP performed laboratory experiments. All authors participate of the data analysis and draft the manuscript and approved the final version.

\section{Funding source}

A.B.L. is supported by the Conselho Nacional de Desenvolvimento Científico e Tecnológico (CNPq) - grant 304538/2012-4. The funders had no role in study design, data collection and analysis, decision to publish or preparation of the manuscript.

\section{Author details}

'Department of Physiology and Pharmacology, Faculty of Medicine, Federal University of Ceara, Fortaleza, Ceara, Brazil. ²Department of Clinical Medicine, Faculty of Medicine, Federal University of Ceará, Fortaleza, Ceara, Brazil. ${ }^{3}$ Hospital Dona Libânia, Fortaleza, Ceara, Brazil. ${ }^{4}$ Department of Clinical and Toxicological Analysis, Faculty of Pharmacy, Federal University of Ceara, Fortaleza, Ceara, Brazil. ${ }^{5}$ Post-Graduation Program in Collective Health, University of Fortaleza, Fortaleza, Ceara, Brazil.

Received: 3 May 2014 Accepted: 12 August 2014

Published: 20 August 2014

\section{References}

1. Global leprosy: Update on the 2012 situation. Wkly Epidemiol Rec 2013, 88:365-379.

2. Ridley DS, Jopling WH: Classification of leprosy according to immunity. A five-group system. Int J Lepr Other Mycobact Dis 1966, 34:255-273.

3. Nakayama EE, Ura S, Fleury RN, Soares V: Renal lesions in leprosy: a retrospective study of 199 autopsies. Am J Kidney Dis 2001, 38:26-30.

4. Al-Mohaya SA, Coode PE, Alkhder AA, Al-Suhaibani MO: Renal granuloma and mesangial proliferative glomerulonephritis in leprosy. Int J Lepr Other Mycobact Dis 1988, 56:599-602.

5. Ahsan N, Wheeler DE, Palmer BF: Leprosy-associated renal disease: case report and review of the literature. J Am Soc Nephrol 1995, 5:1546-1552.

6. Kim MJ, Tam FWK: Urinary monocyte chemoattractant protein-1 in renal disease. Clin Chim Acta 2011, 412:2022-2030.

7. Wada T, Furuichi K, Sakai N, Iwata Y, Yoshimoto K, Shimizu M, Takeda SI, Takasawa K, Yoshimura M, Kida H, Kobayashi Kl, Mukaida N, Naito T, Matsushima K, Yokoyama H: Up-regulation of monocyte chemoattractant protein-1 in tubulointerstitial lesions of human diabetic nephropathy. Kidney Int 2000, 58:1492-1499.

8. Moresco RN, Sangoi MB, De Carvalho JA, Tatsch E, Bochi GV: Diabetic nephropathy: traditional to proteomic markers. Clin Chim Acta 2013, 421:17-30.

9. Xu GW, Yao QH, Weng QF, Su BL, Zhang X, Xiong JH: Study of urinary 8-hydroxydeoxyguanosine as a biomarker of oxidative DNA damage in diabetic nephropathy patients. J Pharm Biomed Anal 2004, 36:101-104.

10. Nin JW, Jorsal A, Ferreira I, Schalkwijk CG, Prins MH, Parving HH, Tarnow L, Rossing P, Stehouwer CD: Higher plasma levels of advanced glycation end products are associated with incident cardiovascular disease and all-cause mortality in Type 1 diabetes A 12-year follow-up study. Diabetes Care 2011, 34:442-447.

11. Daher EF, Silva GB, Cezar LC, Lima RS, Gurjão NH, Mota RM, Abreu KL, Rocha NA, Oliveira MJ, Libório AB: Renal dysfunction in leprosy: a historical cohort of 923 patients in Brazil. Trop Doct 2011, 41:148-150. 
12. Singh Usha RG, Rathore SS, Behura SK, Singh NK: Urinary MCP-1 as diagnostic and prognostic marker in patients with lupus nephritis flare. Lupus 2012, 21:1214-1218.

13. Nauta FL, Scheven L, Meijer E, van Oeveren W, de Jong PE, Bakker SJ, Gansevoort RT: Glomerular and tubular damage markers in individuals with progressive albuminuria. Clin J Am Soc Nephrol 2013, 8:1106-1114.

14. Yamada Y, Matsumoto K, Hashimoto N, Saikusa M, Homma T, Yoshihara S, Saito H: Effect of Th1/Th2 cytokine pretreatment on RSV-induced gene expression in airway epithelial cells. Int Arch Allergy Immunol 2011, 154:185-194.

15. Seok SJ, Lee ES, Kim GT, Hyun M, Lee JH, Chen S, Choi R, Kim HM, Lee EY, Chung $\mathrm{CH}$ : Blockade of CCL2/CCR2 signalling ameliorates diabetic nephropathy in db/db mice. Nephrol Dial Transplant 2013, 28:1700-1710.

16. Murussi M, Campagnolo N, Beck MO, Gross JL, Silveiro SP: High-normal levels of albuminuria predict the development of micro- and macroalbuminuria and increased mortality in Brazilian Type 2 diabetic patients: an 8-year follow-up study. Diabet Med 2007, 24:1136-1142.

17. Kirsztajn GM, Nishida SK, Silva MS, Ajzen H, Pereira AB: Renal abnormalities in leprosy. Nephron 1993, 65:381-384.

doi:10.1186/1471-2334-14-451

Cite this article as: Meneses et al:: Urinary monocyte chemotactic protein-1 (MCP-1) in leprosy patients: increased risk for kidney damage. BMC Infectious Diseases 2014 14:451.

\section{Submit your next manuscript to BioMed Central and take full advantage of:}

- Convenient online submission

- Thorough peer review

- No space constraints or color figure charges

- Immediate publication on acceptance

- Inclusion in PubMed, CAS, Scopus and Google Scholar

- Research which is freely available for redistribution 